Document downloaded from:

http://hdl.handle.net/10251/78994

This paper must be cited as:

Caselles, E.; Valor, E.; Abad Cerdá, FJ.; Caselles, V. (2012). Automatic classification-based generation of thermal infrared land surface emissivity maps using AATSR data over Europe. Remote Sensing of Environment. 124:321-333. doi:10.1016/j.rse.2012.05.024.

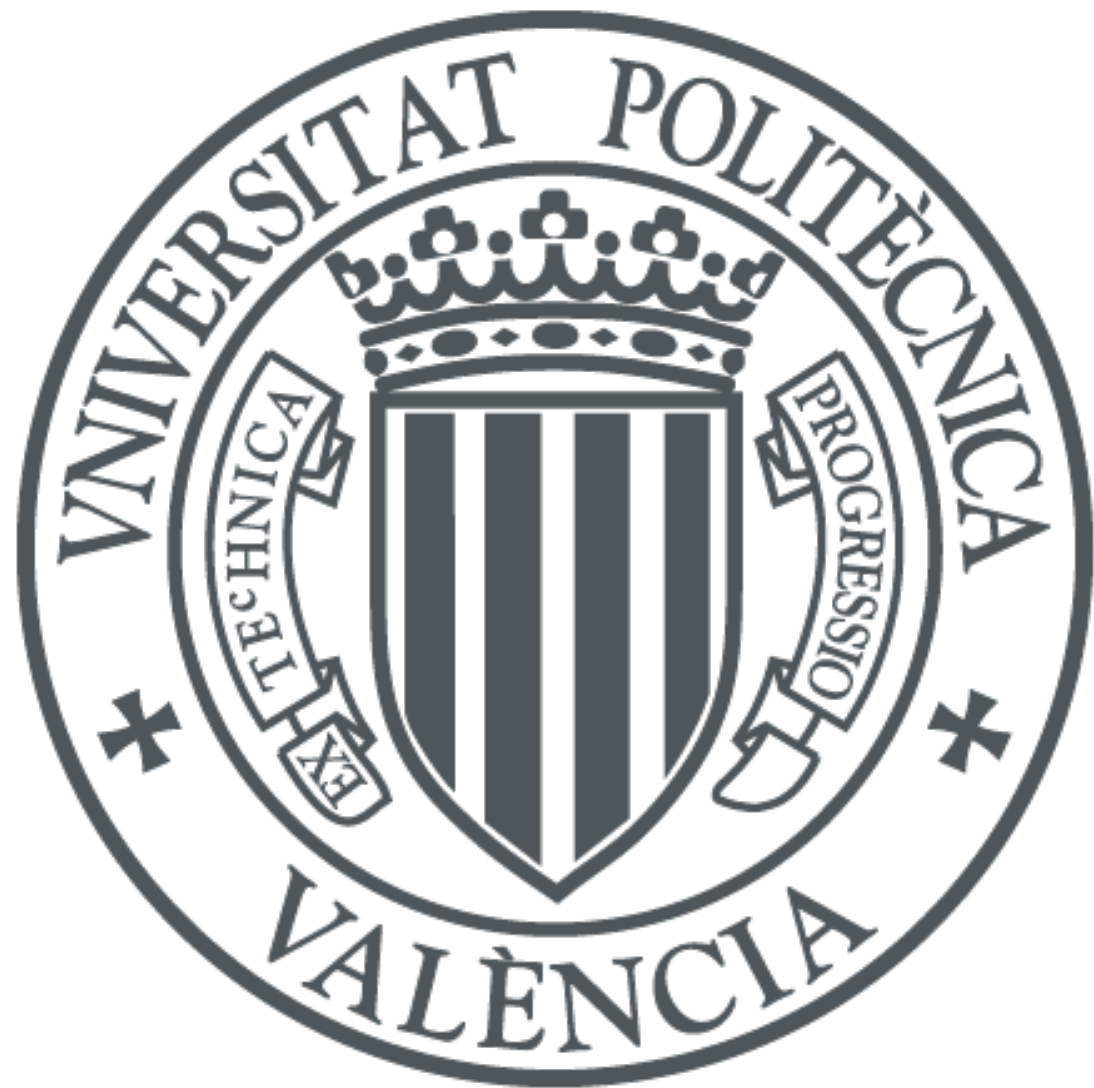

The final publication is available at

http://dx.doi.org/10.1016/j.rse.2012.05.024

Copyright Elsevier

Additional Information

This is the author's version of a work that was accepted for publication in Remote Sensing of Environment. Changes resulting from the publishing process, such as peer review, editing, corrections, structural formatting, and other quality control mechanisms may not be reflected in this document. Changes may have been made to this work since it was submitted for publication. A definitive version was subsequently published in Remote Sensing of Environment, 124, 321-333.DOI :10.1016/j.rse.2012.05.024. 


\title{
Automatic classification-based generation of thermal infrared land surface emissivity maps using AATSR data over Europe
}

E-mail: eduardo.caselles@uv.es

\author{
$\underline{\text { Eduardo Caselles }}^{1}$
}

Phone: +34963543121

Fax: +34 96. 3543385

Permanent Address: Department of Earth Physics and Thermodynamics, Faculty of Physics, University of

Valencia. C/ Dr. Moliner, 50. E - 46100 Burjassot, Spain.

$$
\text { Enric Valor }{ }^{1} \text {, Francisco J. Abad }{ }^{2} \text {, Vicente Caselles }{ }^{1}
$$

${ }^{I}$ Department of Earth Physics and Thermodynamics, University of Valencia.

C/Dr. Moliner, 50. 46100 Burjassot, Spain.

${ }^{2}$ Department of Information Systems and Computation, Technical University of Valencia.

Camino de Vera s/n. 46022 Valencia, Spain.

\begin{abstract}
The remote sensing measurement of land surface temperature from satellites provides a monitoring of this magnitude on a continuous and regular basis, which is a critical factor in many research fields such as weather forecasting, detection of forest fires or climate change studies, for instance. The main problem of measuring temperature from space is the need to correct for the effects of the atmosphere and the surface emissivity. In this work an automatic procedure based on the Vegetation Cover Method, combined with the GLOBCOVER land surface type classification, is proposed. The algorithm combines this land cover classification with remote sensing information on the vegetation cover fraction to obtain land surface emissivity maps for AATSR split-window bands. The emissivity estimates have been compared with ground measurements in two validation cases in the area of rice fields of Valencia, Spain, and they have also been compared to the classification-based emissivity product provided by MODIS (MOD11_L2). The results show that the error in emissivity of the proposed methodology is of the order of \pm 0.01 for
\end{abstract}


most of the land surface classes considered, which will contribute to improve the operational land surface temperature measurements provided by the AATSR instrument.

KEYWORDS: land surface temperature, land surface emissivity, vegetation cover, AATSR, Globcover. 


\section{INTRODUCTION}

2 The remote sensing measurement of land surface temperature (LST) using thermal

3 infrared (TIR) data provided by instruments placed in satellites provides a monitoring of

4 this magnitude on a synoptic, continuous and regular basis. The analysis of its evolution

5 in time and space is a critical factor in many research fields such as weather forecasting,

6 detection and monitoring of forest fires, natural hazards, climate change watch, energy

7 fluxes estimation, etc. (Lentile et al. 2006, Zukhov et al. 2006, Tralli et al. 2005, Jin and

8 Liang 2006, Anderson et al. 2008, Liang et al. 2010).

9 The main problem of measuring LST from remote sensing instruments is the need

10 to correct the effects of the atmosphere in the measured signal and the knowledge of land

11 surface emissivity (LSE). The atmospheric correction can be addressed with the use of

12 radiative transfer models (RTM) with a description of the atmospheric temperature and

13 humidity distributions (Cristóbal et al. 2009, Coll et al. 2010, Coll et al. 2012a, Zhou et

14 al. 2012), or by means of multichannel (split-window) or multiangle (dual-angle)

15 algorithms (Coll et al. 2006, Sòria and Sobrino 2007, Yu et al. 2008). In any of these

16 cases, an independent estimation of LSE is needed, since these algorithms usually (but

17 not always) show an explicit dependence on it.

18 Different methodologies have been developed to produce emissivity maps of the

19 surface: emissivity-temperature separation algorithms such as TES (Gillespie et al. 1998)

20 or TISI (Li and Becker 1993), multitemporal methods (Watson 1992, Wan and Li 1997),

21 or algorithms based on physical models of the surface and estimations of fractional

22 vegetation cover through spectral indices (Valor and Caselles 1996). The algorithms

23 based on vegetation indices provide a practical way to estimate LSE with an acceptable 
24 accuracy (around $1 \%$ to $2 \%$ of error) at the typical split-window channels, as is the case

25 of the Advanced Along-Track Scanning Radiometer (AATSR) instrument onboard the

26 Envisat platform, and for those instruments that only have one TIR channel (e.g. Landsat-

27 Thematic Mapper).

28 In this work, a procedure is presented to produce LSE maps based on the algorithm

29 proposed by Valor and Caselles (1996), the so-called vegetation cover method (VCM),

30 combined with the GLOBCOVER land surface classification (Arino et al. 2008), and a

31 dynamic estimation of vegetation fraction from AATSR visible and near infrared bands.

32 The proposed method is similar to some extent to the algorithm for LSE estimation used

33 by the LST product of Terra-MODIS (Snyder et al. 1998), and for LSE estimations in

34 Meteosat-SEVIRI (Peres and DaCamara 2005; Trigo et al. 2008). Although this

35 methodology can be applied to any TIR sensor, in the present paper it is specifically

36 applied to the AATSR instrument, since at present no LSE maps at 1-km spatial

37 resolution are available for that sensor.

38 Initially, the algorithm has been applied at European scale, although it will be used

39 to produce global LSE maps in the near future. This procedure will contribute to the

40 improvement of LST estimates from AATSR data, since the current operational

41 algorithm (Noyes et al. 2007) has been recognized to fail in some cases (with errors in the

42 range $2-5 \mathrm{~K}$ ) due to the use of surface classification and vegetation cover static maps at

43 an spatial resolution of $0.5^{\circ} \times 0.5^{\circ}$, which is insufficient to cope with real surface

44 heterogeneity in most cases (Coll et al. 2006, Coll et al. 2009, Noyes et al. 2007).

45 The paper proceeds as follows. First, the developed algorithm is presented in detail.

46 In the results section a sensitivity analysis is performed for the LSE of all considered 
47 classes, and monthly mean emissivity maps for AATSR over Europe on 2007 are

48 presented and analyzed. Finally, the main conclusions arising from this work are given.

\section{METHODOLOGY}

The LSE is calculated using the vegetation cover method (Valor and Caselles

51 1996), which is based on the geometric model proposed by Caselles and Sobrino (1989).

52 The model defines the effective emissivity for a rough and heterogeneous surface from its

53 component emissivities, and from an estimation of the fractional vegetation cover. In this

54 method, the emissivity in band $\mathrm{k}$ is estimated through the relationship:

$55 \quad \varepsilon_{\mathrm{k}}=\varepsilon_{\mathrm{kv}} \mathrm{f}+\varepsilon_{\mathrm{kg}}(1-\mathrm{f})+4<\mathrm{d} \varepsilon_{\mathrm{k}}>\mathrm{f}(1-\mathrm{f})$

56 where $\varepsilon_{\mathrm{kv}}$ and $\varepsilon_{\mathrm{kg}}$ are the vegetation and ground emissivity, respectively, $<\mathrm{d} \varepsilon_{\mathrm{k}}>$ is the

57 maximum cavity term, and $\mathrm{f}$ is the fractional vegetation cover. The cavity term (the third

58 term in the right-hand side of equation (1)) takes into account the effect of radiance

59 internal reflections between the different components of a structured and rough surface

60 (Caselles and Sobrino 1989).

61 The coefficients $\varepsilon_{\mathrm{kv}}, \varepsilon_{\mathrm{kg}}$ and $<\mathrm{d} \varepsilon_{\mathrm{k}}>$ depend on the surface type and spectral channel.

62 To calculate them, it is first needed a classification of the surface to determine the

63 vegetation and soil types and surface geometric structure found in a given area. Different

64 operational classification schemes are available at present, among which we have

65 considered the IGBP DISCover based on AVHRR data (Loveland et al. 2000), the

66 MODIS Land Cover type product (Friedl et al. 2002; Friedl et al. 2010), the CORINE

67 land cover based on Thematic Mapper data (Buttner et al. 2004), and the GLOBCOVER

68 (GLC) dataset based on Medium Resolution Imaging Spectrometer (MERIS) data 
69 (Bicheron et al., 2008; Arino et al. 2008). They have been compared in terms of

70 classification accuracy in several areas and different contexts (Herold et al. 2008; See and

71 Fritz 2006; Jung et al. 2006; Neumann et al. 2007; Heiskanen 2008; Wu et al. 2008),

72 concluding that the key factor to assure classification accuracy is a good spatial

73 resolution (Herold et al., 2008; Heiskanen, 2008). For this reason, the GLC dataset was

74 selected since it shows the best combination of spatial $(300 \mathrm{~m})$ and spectral resolution

75 presently. It is generated from Envisat-MERIS data, with reasonably good spectral

76 resolution, using an unsupervised classification regional expert-tuned procedure similar

77 to the predecessor GLC2000 classification (Bartholomé and Belward 2005), and is

78 compatible with the standardized legend of the United Nations Food and Agriculture

79 Organization Land Cover Classification System (LCCS, Di Gregorio and Jansen 2000).

80 The GLC dataset was used to derive the surface type maps needed to set the emissivity

81 coefficients of equation (1).

82 The initial 22 classes provided by the regional Western Europe GLC dataset were

83 grouped and reduced to only 10 classes taking into account the components (soil and

84 vegetation; bare rock; water, snow or ice; manmade construction materials, etc.) included

85 in each class and the similarity between surface geometric structures. For the case of

86 vegetated surfaces, the classes were grouped attending to structure (low grasses/crops,

87 shrubs/trees lower than $5 \mathrm{~m}$, shrubs/trees higher than $5 \mathrm{~m}$ ), background surface (soil or

88 water depending on flooding conditions), and vegetation type (green grasses, evergreen

89 or deciduous shrubs/trees). All the classes corresponding to bare surfaces were also

90 grouped into a single one, and the classes for urban areas, water, and snow and ice were

91 maintained separately. Table 1 shows the resulting emissivity classes and the original 
92 GLC surface types. The two first emissivity classes include those areas that are flooded

93 or heavily irrigated most of the year, having water as surface background, with low (class

94 1) or high (class 2) vegetation, and with different fractional vegetation cover. Classes 3

95 and 4 contain areas with vegetation of low and medium height and dry soil as

96 background. Classes 5 and 6 refer to forested areas with mainly deciduous or evergreen

97 vegetation, respectively. Class 7 is regarded to urban built areas, and class 8 to bare

98 surfaces (deserts, rocks, gravels, etc.). These bare surfaces, dominant in arid and semi-

99 arid regions, may have the widest range of emissivity values, and thus may have a

100 significant impact on emissivity estimation and on LST retrievals if one single value is

101 used for them. Although these areas represent less than $1 \%$ of the pixels over Europe,

102 additional efforts will be needed in future versions of the algorithm to distinguish

103 between different bare surfaces, and thus to assign more adequate emissivity values in

104 each case. Finally, classes 9 and 10 are related to water bodies, and areas permanently

105 covered by snow and ice.

106 A set of coefficients $\varepsilon_{\mathrm{kv}}, \varepsilon_{\mathrm{kg}}$ and $<\mathrm{d} \varepsilon_{\mathrm{k}}>$ were derived for each of the emissivity

107 classes established in Table 1, using the spectra included in the Advanced Spaceborne

108 Thermal Emission and Reflection Radiometer (ASTER) Spectral Library (Baldridge et al.

109 2009), which is the most extensive published dataset of TIR reflectance spectra including

110 both natural (soils, rocks, vegetation, minerals) and manmade (asphalt, tar, concrete,

111 brick, tile) materials to date. Table 2 gives the values of these coefficients for equation

112 (1) in the case of vegetated areas (classes 1 to 6), or alternatively average single-value

113 emissivities in the case of non-vegetated surfaces (classes 7 to 10 corresponding to urban,

114 bare rock, water, snow and ice). In all cases the used spectra were first convolved with 
115 the AATSR spectral response curves for bands at 11 and $12 \mu \mathrm{m}$ to get the channel 116 emissivity values.

117 For the case of vegetated surfaces (classes 1 to 6), the emissivity values for 118 vegetation and ground (or water) were calculated using the samples given in the ASTER

119 Spectral Library. These values were then averaged for the selected samples. In the case of 120 soils, all available samples in the library (52) were used, which showed low variability in 121 these bands (standard deviation smaller than \pm 0.005 ). There are only four vegetation 122 samples. For classes 1 and 3, the green grass sample was used, for classes 2 and 4, the 123 average between conifer and deciduous samples, for class 6 the conifer sample, and for 124 class 5 the deciduous sample; the considered values for each class are in agreement, 125 within the error, with measurements of complete plants for similar vegetation samples 126 (Rubio et al. 2003). Rocks were excluded since they should not be usual in these surface 127 types.

128 The classes showing low vegetation (1 and 3) were assigned a maximum cavity 129 term $<\mathrm{d} \varepsilon_{\mathrm{k}}>=0$, since they are almost flat and show no cavities. For vegetated surfaces 130 with a significant structure (emissivity classes 2, 4, 5 and 6) the maximum cavity term 131 was determined with a simulation procedure. According to Caselles and Sobrino (1989), 132 the cavity term for near nadir observation is given by

$133 \mathrm{~d} \varepsilon_{\mathrm{k}}=\left(1-\varepsilon_{\mathrm{kg}}\right) \varepsilon_{\mathrm{kv}} \mathrm{F}(1-\mathrm{f})$

134 where $\mathrm{F}$ is a shape factor that depends on the height $(\mathrm{H})$ and separation $(\mathrm{S})$ between the 135 surface elements, and considers the energy transmission between them, 
$136 \quad F=\left(1+\frac{H}{S}\right)-\sqrt{1+\left(\frac{H}{S}\right)^{2}}$.

137 The $d \varepsilon_{\mathrm{k}}$ term was simplified and parameterized in terms of fractional vegetation

138 cover only, and a maximum cavity term was calculated $\left(<\mathrm{d} \varepsilon_{\mathrm{k}}>\right.$ in equation (1)), which

139 represents the maximum value that it can take for a given surface geometry with the

140 fractional cover ranging from 0 to 1 (Valor and Caselles 1996); the resulting simplified

141 expression is the third term in the right-hand side of equation (1). The maximum cavity

142 term was calculated using equation (2) with the following procedure. First, for a given

143 class reasonable values for the height $(\mathrm{H})$ and size $(\mathrm{L})$ of the vegetation elements were

144 assigned taking into account the vegetation description given by the GLC dataset. In

145 particular, for classes 2 and 4 (shrubs/trees lower than $5 \mathrm{~m}$ ) values of $\mathrm{H}=(3 \pm 1) \mathrm{m}$ and

$146 \mathrm{~L}=(3 \pm 1) \mathrm{m}$ were taken; and for classes 5 and 6 (shrubs/trees higher than $5 \mathrm{~m}$ ) values of

$147 \mathrm{H}=(15 \pm 5) \mathrm{m}$ and $\mathrm{L}=(5 \pm 2) \mathrm{m}$ were considered, as mean values and standard deviations for

148 each structure parameter. Secondly, for the vegetation fraction ranging from 0 to 1 , the

149 separation $\mathrm{S}$ and shape factor $\mathrm{F}$ were calculated for each $\mathrm{f}$ value, and then the cavity term

150 given by equation (2) was calculated using the vegetation and ground/water emissivities

151 described above. Finally, the maximum value of the cavity term was selected. The

152 variability in the emissivity coefficients and in the structural parameters (height and size)

153 were taken into account considering the vegetation and ground emissivities, and height

154 and size of vegetation elements, as random variables following a Gaussian distribution

155 with mean values and standard deviations given in table 2 ( for emissivities) and above

156 (for structural parameters). In consequence, the maximum value of the cavity term was

157 calculated with this random procedure in 80 different simulations, and the average value 
158 and the standard deviation of the 80 results obtained were assigned to the value of the

159 maximum cavity term given in table 2.

160 For the non-vegetated surfaces, average values were calculated from the samples

161 provided by the ASTER Spectral Library. In the case of bare rock, 389 rock samples

162 were averaged; 2 samples for water (sea and tap water), and 4 for snow and ice (fine,

163 medium and coarse granular snow, and ice), giving unique effective values for each

164 AATSR band. Certainly, rock emissivities show high standard deviations, and probably it

165 would be necessary to distinguish them using additional rock maps in the future. In any

166 case, the percentage of rock-exposed surfaces is relatively small in the GLC database for

167 the area considered in this work, only $0.85 \%$ of pixels.

168 Finally, effective emissivity values were calculated for urban areas using the 169 spectra for manmade materials: tiles and rubber were considered for roof emissivities, 170 concrete for walls, and asphalt for paving. The effective emissivity was calculated 171 adapting the model of Caselles and Sobrino (1989) to this kind of surfaces for near-nadir 172 observation conditions:

$173 \varepsilon_{\mathrm{k}}=\varepsilon_{\mathrm{kr}} \mathrm{P}_{\mathrm{r}}+\varepsilon_{\mathrm{kp}}\left(1-\mathrm{P}_{\mathrm{r}}\right)+\left(1-\varepsilon_{\mathrm{kp}}\right) \varepsilon_{\mathrm{kw}} \mathrm{F}\left(1-\mathrm{P}_{\mathrm{r}}\right)$

174 where $\varepsilon_{\mathrm{kr}}, \varepsilon_{\mathrm{kp}}$ and $\varepsilon_{\mathrm{kw}}$ are roof, paving and wall emissivities, $\mathrm{P}_{\mathrm{r}}$ is the percentage of 175 observed roofs, and $\mathrm{F}$ is the shape factor described above that depends on height and 176 separation of buildings. The percentage of observed roofs was ranged from 0.2 (areas 177 with wide streets and dispersed buildings, in which roofs occupy $20 \%$ of the surface) to 1780.8 (areas with narrow streets and a high concentration of buildings close to each other, in 179 which roofs occupy $80 \%$ of the observed surface). The shape factor in turn was changed 
180 from 0.5 (low height buildings in wide avenue areas) to 10 (very high buildings in narrow 181 street areas).

182 Fractional vegetation cover (f) required in equation (1) was calculated from 183 normalized difference vegetation index (NDVI) and reflectance values in AATSR red

$184(0.659 \mu \mathrm{m})$ and near infrared $(0.865 \mu \mathrm{m})$ bands using the relationship proposed by Valor

185 and Caselles (1996). This relationship was derived using a linear mixture model with two

186 components (soil and vegetation) that defines the channel reflectance of a mixed pixel as

187 a combination of the soil and vegetation reflectance weighted by the fractional vegetation

188 cover. Using this definition the fractional vegetation cover can be written in terms of

189 NDVI as (Valor and Caselles 1996):

190

$$
\mathrm{f}=\frac{\left(1-\frac{\mathrm{NDVI}}{\mathrm{NDVI}_{\mathrm{s}}}\right)}{\left(1-\frac{\mathrm{NDVI}}{\mathrm{NDVI}_{\mathrm{s}}}\right)-\mathrm{K}\left(1-\frac{\mathrm{NDVI}}{\mathrm{NDVI}_{\mathrm{v}}}\right)}
$$

191 where NDVI is the pixel vegetation index, $\mathrm{NDVI}_{\mathrm{s}}$ and $\mathrm{NDVI}_{\mathrm{v}}$ are the index values for

192 bare soil and full vegetation, and factor $\mathrm{K}$ is

$193 \quad K=\frac{\rho_{\text {NIRv }}-\rho_{R v}}{\rho_{\text {NIRs }}-\rho_{R s}}$

194 where $\rho_{\mathrm{Rv}}$ and $\rho_{\mathrm{NIRv}}$ are respectively the red and near infrared reflectance values over full

195 vegetation, and $\rho_{\mathrm{Rs}}$ and $\rho_{\mathrm{NIRs}}$ are the corresponding reflectances over bare soil. All these

196 coefficients can be extracted from the AATSR scene itself, searching for the maximum

197 and minimum NDVI values over the scene. 
199 channels at $0.659 \mu \mathrm{m}$ and $0.865 \mu \mathrm{m}$, the land cover classification GLC, and the

200 emissivity coefficients by class given in table 2 . The system obtains the coordinates of a 201 given pixel and the measured values at each AATSR channel. The GLC map is used

202 simultaneously to obtain the ground type of the pixel given by the coordinates of the

203 AATSR scene. Since GLC data have a spatial resolution of $300 \mathrm{~m}$, while AATSR data

204 have a $1 \mathrm{~km}$ resolution, the system uses an interpolation by proportion of occupied areas

205 algorithm (see Figure 1), to be able to combine them accurately, based on the 206 geographical coordinates of both data sets.

207 This interpolation algorithm obtains the different types of vegetation and soil that 208 form each AATSR pixel and estimates the proportion of the area that each vegetation and

209 soil type represents. All 300m pixels within or partially overlapping the coarser $1 \mathrm{~km}$

210 pixels are first identified, along with their respective land cover classes. Subsequently,

211 the exact area of each GLC pixel overlapped by the AATSR pixel is calculated, based on

212 their geographical coordinates and spatial resolutions. Therefore, the algorithm is able to

213 estimate the values that need to be applied to the coefficients of equation (1). Each one is

214 calculated as the weighted average of the values for that coefficient, related to all the

215 emissivity classes involved. Thereby, the influence of each emissivity class is determined

216 by the percentage that its area represents in the total area occupied by the AATSR pixel.

217 The use of these weighted average coefficients for the vegetation and ground emissivities

218 will minimize the error of estimate in emissivity, since this procedure accounts for the

219 heterogeneity within each AATSR $1 \mathrm{~km}$ pixel that is captured by the higher spatial 220 resolution of GLC. The error of the interpolation method is lower than $1 \%$, which is the 
221 error of the VCM model used to obtain the emissivity (see subsection 3.1 below).

222 Therefore, the error derived from interpolating the GLC pixels with the AATSR ones is

223 not significant compared to the error of the model.

224 The whole processing algorithm is summarized in the flowchart shown in Figure 2.

225 First, the NDVI is calculated for all non-cloudy pixels on a daily basis, using the cloud

226 mask provided by the AATSR product. Then, a procedure is started to search for the

227 maximum and minimum NDVI values of the scene, and their respective reflectances,

228 needed in equations (5) and (6) to calculate the fractional vegetation cover. In this

229 procedure all pixels classified as bare rock, urban, water, snow or ice surfaces by GLC

230 are excluded. For the surfaces classified as natural vegetation, the system checks that the

231 surface is not accidentally covered by water, snow or ice, which can be the case mostly in

232 winter scenes. In the case of water a threshold is used for the vegetation index values: if

$233 \mathrm{NDVI}<-0.10$ then the pixel is considered water, taking into account that usually the

234 reflectance over water is smaller in the near infrared than in the red channels.

235 To detect snow- or ice-covered surfaces, an algorithm based on the MODIS snow-

236 cover mapping procedure was used, which combines the reflectance in AATSR near

237 infrared channel $(0.865 \mu \mathrm{m})$ and the Normalized Difference Snow Index (NDSI)

238 calculated as (Riggs et al. 2000; Hall et al. 2002):

$239 \quad \mathrm{NDSI}=\frac{\rho_{\mathrm{G}}-\rho_{\mathrm{SWIR}}}{\rho_{\mathrm{G}}+\rho_{\mathrm{SWIR}}}$

240 where $\rho_{\mathrm{G}}$ and $\rho_{\mathrm{S} w I R}$ are the reflectances in AATSR green $(0.555 \mu \mathrm{m})$ and short-wave

241 infrared $(1.6 \mu \mathrm{m})$ channels, respectively. If NDSI is higher than 0.4 , and reflectance in

242 the near infrared band is larger than 0.11 , then the surface is ice- or snow-covered (Hall et 
243 al. 2002). However, if the green band reflectance is lower than 0.10 , then the pixel will

244 not be ascribed as snow even if the other conditions are fulfilled, preventing pixels with

245 very dark targets from being erroneously mapped as snow. All pixels identified as water

246 or snow with these procedures, are later assigned the corresponding emissivity values

247 given in table 2.

248 Once cloudy, snow- or water-covered pixels have been identified, the system

249 produces a histogram of NDVI with the remaining pixels over the scene. The minimum

250 and maximum NDVI values (for bare soil and vegetation) needed in equation (5) are

251 selected as the values located at the $5^{\text {th }}$ and $95^{\text {th }}$ percentiles of the distribution,

252 respectively, to assure that the selected values are representative of the whole scene and

253 are not spurious values. For these minimum and maximum NDVI thresholds, the

254 corresponding reflectances in the red and near infrared bands are collected to calculate

255 the $\mathrm{K}$ factor in equation (6). Once the thresholds are established, the software calculates

256 the fractional vegetation cover for vegetated surfaces, selects the emissivity coefficients

257 depending on the GLC class from Table 2, and calculates effective emissivity with

258 equation (1), or alternatively assigns directly the effective emissivity for non-vegetated

259 surfaces. In this step, it is checked for the two first classes (flooded areas) if they are

260 actually flooded or not, in order to select the adequate $\varepsilon_{\mathrm{g}}$ value (water or soil).

261 This procedure is followed for all available daily scenes within each month,

262 allowing the processing of all respective orbits and dates, from which daily emissivity

263 maps are produced. Then, a monthly composite is produced for each orbit by calculating

264 the average, maximum and minimum valid emissivity values at each pixel over the 
265 month. Finally, the different orbits are merged to produce the final monthly emissivity

266 map for Europe.

267 In order to minimize the impact of missing values of monthly emissivity on the 268 retrieval of LST, a backup procedure is followed by the system to reduce the number of

269 non-processed LST pixels. First, in order to estimate the minimum number of valid

270 AATSR observations per month needed for the production of reliable emissivity

271 estimates, the standard deviation of daily emissivities within a month were calculated to

272 check what the variability in terms of emissivity is. The results showed that the monthly

273 variability in emissivity is of the order of $0.004 \pm 0.002$ in average on the whole scene,

274 which is lower than the emissivity error of estimate given in the sensitivity analysis (see

275 subsection 3.1). With this low variability, one single observation in a month can be a

276 good approximation to an estimate of the monthly emissivity of a given pixel. If no

277 observation is available in a given month, then the second approximation is to interpolate

278 the emissivity value in that month by using the emissivity values corresponding to the

279 previous month and the following month, respectively. Finally, for pixels that are covered

280 by clouds most of the year, the third approach to the problem is the use of climatological

281 averages to estimate a monthly value of NDVI, from which to calculate the monthly

282 emissivity as described above.

\section{3. RESULTS AND DISCUSSION}

\subsection{Sensitivity analysis}


An error analysis of the emissivities calculated with the described methodology

286 was conducted using error propagation theory. Following equation (1), the error in 287 emissivity is given by:

$288 \delta \varepsilon=f \delta \varepsilon_{v}+(1-f) \delta \varepsilon_{g}+4 f(1-f) \delta<d \varepsilon>+\left[\varepsilon_{v}-\varepsilon_{g}+4<\varepsilon>(1-2 f)\right] \delta f$

289 where $\delta \varepsilon_{\mathrm{v}}, \delta \varepsilon_{\mathrm{g}}$ and $\delta<\mathrm{d} \varepsilon>$ are the errors in the emissivity coefficients of equation (1),

290 which are given in table 2, and $\delta \mathrm{f}$ is the error in the vegetation fraction. Methods that

291 retrieve fractional vegetation cover from NDVI using linear relationships provide $\mathrm{f}$ with

292 errors ranging from \pm 0.04 to \pm 0.20 (Gutman and Ignatov 1998, Zeng et al. 2000, Xiao

293 and Moody 2005, Jiang et al. 2006, Zhou et al. 2009, Verger et al. 2009). The algorithm

294 proposed in the present paper (Eq. (5)) uses a linear relationship between vegetation

295 cover and reflectance, which implies a non-linear relationship between $\mathrm{f}$ and NDVI,

296 capturing the non-linearity actually observed, especially at high values of vegetation

297 fraction (for which NDVI usually saturates). For this kind of non-linear algorithms errors

298 of \pm 0.08 in the fractional vegetation cover retrieval have been reported (Purevdorj et al.

299 1998). In particular, Jiang et al. (2006) analyzed the performance of a non-linear

300 algorithm based on linear relationships between reflectance and fractional vegetation

301 cover (the so-called Scaled Difference Vegetation Index, SDVI) equivalent to the

302 methodology here proposed, and found that it was able to provide $f$ with an uncertainty of

$303 \pm 0.07$ in a validation exercise. In consequence, a value of \pm 0.15 in $\delta f$ has been used to

304 address the sensitivity analysis, which is twice the error values reported for that type of

305 algorithm, and is of the same order of magnitude than the higher errors observed in linear 306 algorithms. 
Table 3 shows the average, maximum, minimum and standard deviation of the

308 errors in emissivity for $\mathrm{f}$ values raging from 0 to 1 in each class corresponding to

309 vegetated areas, and the average error calculated for non-vegetated zones. The lowest

310 errors correspond to flooded areas (classes 1 and 2 with water at the background),

311 croplands/grasslands (class 3), and urban, water and snow/ice areas (classes 7, 9 and 10)

312 with values from \pm 0.001 to \pm 0.008 , which would result in LST errors from \pm 0.1 to $\pm 0.6 \mathrm{~K}$

313 (Galve et al. 2008). The largest error in emissivity is found in the bare rock case (class 8)

314 with a value of \pm 0.05 , due to the high variability of this kind of surfaces, which would

315 produce an LST error around $\pm 4 \mathrm{~K}$. Although these areas occupy a small fraction of the

316 total surface considered, it would be desirable to use rock maps in the future to refine the

317 methodology in those areas. The remaining classes (4,5 and 6) show errors in emissivity

318 around \pm 0.014 that would correspond to LST errors of about $\pm 1 \mathrm{~K}$.

\section{3.2. Emissivity product for AATSR}

320 Monthly emissivity maps of Europe were produced with the proposed procedure

321 for year 2007, using all available AATSR images for each month, processing a total of

3222,257 scenes in the whole year. Figure 3 shows the monthly fractional vegetation cover

323 for each month calculated as the average value of each valid pixel within each month. It

324 is observed a variation of vegetation cover in Europe during the year with peaks in spring

325 and autumn, and lower vegetation fractions in summer and especially in winter. The low

326 coverage in some mountainous areas such as the Scandinavian Peninsula, the Alps or the

327 Pyrenean Mountains in winter months, is due to the presence of snow and water. Figure 4

328 presents the monthly emissivity for band AATSR-11 $\mu$ m; the emissivity variation in each

329 month (difference between maximum and minimum emissivity value in a pixel basis, not 
330 shown) was calculated resulting in negligible values for most pixels, giving confidence in

331 the stability of the proposed method.

332 To test the consistency of the methodology, the time evolution of fractional

333 vegetation cover and emissivity was checked for the emissivity classes defined in Table

334 1, selecting adequate locations for each case. Figure 5 shows the results. For class 1 the

335 area of rice fields in the Albufera of Valencia, Spain $\left(39^{\circ} 15^{\prime} \mathrm{N}, 0^{\circ} 18^{\prime} \mathrm{W}\right)$ was used. In

336 this case the vegetation cover follows the typical phenology of rice plants, which are

337 seeded in May and harvested in September, the fields being completely flooded during

338 this period until January; then the fields are dried, showing scarce and low grasses

339 (January to April), until a new annual period begins. Consequently, emissivity is low in

340 April, increases from May to July (when the vegetation cover is highest), decreases to

341 September (when it is harvested) and peaks again in October and November due to

342 flooded fields without vegetation. For class 3 a cropland area placed near Fondouce,

343 France $\left(46^{\circ} 4^{\prime} \mathrm{N}, 0^{\circ} 53^{\prime} \mathrm{W}\right)$ was selected. In this case the vegetation cover starts from a

344 relatively low value in January, increasing until reaching a maximum value in June and

345 decreasing gradually until January; the emissivity follows the same tendency as

346 vegetation cover does. In class 4 a shrubland area near Tilj, Croatia $\left(43^{\circ} 36^{\prime} \mathrm{N} 16^{\circ} 46^{\prime} \mathrm{E}\right)$

347 was used, showing an irregular variation for vegetation cover during the year and an

348 emissivity with relatively low variability (the values on December are due to the presence

349 of snow). An area in Montebruno, Italy $\left(44^{\circ} 31^{\prime} \mathrm{N}, 9^{\circ} 15^{\prime} \mathrm{E}\right)$ was selected as an example

350 of broadleaved/needleleaved deciduous forest (class 5). The vegetation fractional cover

351 typically increases during the year peaking in summer and decreasing in autumn; since

352 emissivity for the soil (0.970) and the vegetation (0.973) are similar, the effective 
353 emissivity is lower both for low and high vegetation cover fractions, and it is higher at

354 intermediate fractions due to cavity effects, which explain the peak values in spring. In

355 case of class 6 , broadleaved/needleleaved evergreen forest, a site located in Moray,

356 Scotland $\left(57^{\circ} 23^{\prime} \mathrm{N}, 3^{\circ} 49^{\prime} \mathrm{W}\right)$ was analyzed showing low variation both in fractional

357 vegetation cover and emissivities. There were no well-defined areas in the scene for class

3582 (flooded forest/shrubland), and the remaining classes (7 through 10) exhibit constant

359 values with time as expected, since they do not depend on vegetation cover (urban area,

360 bare rock, water, snow and ice).

361 3.3. Validation

362 A validation exercise was conducted comparing the emissivity values produced by

363 the system with concurrent ground measurements carried out in the area of rice fields

364 placed in the Albufera of Valencia, Spain (Coll et al. 2007), during two different

365 moments of the year (see Figure 5, class 1). First, it was compared the emissivity value

366 when the surface is fully covered of rice with water as background (July). In channel

367 AATSR-11 $\mu \mathrm{m}$ the measured emissivity in the field was $0.985 \pm 0.002$ and the system

368 value was $0.982 \pm 0.001$, with a difference of +0.003 , whereas for AATSR- $12 \mu \mathrm{m}$ band

369 the measured emissivity was $0.980 \pm 0.005$ and the system value was $0.988 \pm 0.002$,

370 showing a difference of -0.008 . Secondly, the comparison was conducted on April, when

371 the rice fields are fallow and in dry conditions (Coll et al. 2012b); in this case the

372 measured emissivity in the field was $0.957 \pm 0.005$ (Mira et al. 2007) in channel AATSR-

$37311 \mu \mathrm{m}$ and the system value was $0.970 \pm 0.001$, with a difference of -0.013 , whereas for

374 AATSR $-12 \mu \mathrm{m}$ band the measured emissivity was $0.954 \pm 0.005$ and the system value was

$3750.977 \pm 0.001$, showing a difference of -0.023 . The validation results are within \pm 0.010 , 
376 except for the case of bare soil in channel AATSR-12 $\mu \mathrm{m}$. This shows a reasonably good

377 result, although the validation exercise is very limited in space and time. Nevertheless,

378 the coefficients used for dry bare soils, calculated from all the soil sample spectra of the

379 ASTER library (which showed a low dispersion, see Table 2), will be revised using

380 additional datasets in order to reduce the larger difference observed in channel AATSR-

$38112 \mu \mathrm{m}$.

382

\subsection{Comparison with MODIS emissivity product}

383 A comparison of the AATSR emissivity maps with other similar land surface

384 emissivity products (designed for use in typical split-window channels, and based on a

385 land cover classification) was carried out in order to analyze spatial and temporal

386 patterns. The MODIS classification-based emissivity product (Snyder et al. 1998) was

387 considered taking into account its similarity to the methodology proposed in the present

388 paper. Although the LST product provided by SEVIRI also uses a classification-based

389 emissivity estimate (Peres and DaCamara 2005, Trigo et al. 2008), it is an internal

390 product that was not available to perform the comparison.

391 The selected product is the MODIS/Terra level-2 LST/E data (MOD11_L2), which

392 provides LST measurements using the generalized split-window algorithm (Wan and

393 Dozier, 1996). For this algorithm, emissivity estimates in MODIS split-window bands 31

394 and 32 are needed, which are calculated using the classification-based emissivity method

395 (Snyder et al. 1998) and included also as data in the MOD11_L2 product. This method

396 uses as input the MODIS land cover product (MOD12Q1) provided yearly, and assigns to

397 each class emissivity values that were estimated using kernel models and considering the

398 spectral and structural characteristics of each surface type (Snyder and Wan 1998). The 
399 algorithm also includes dynamical and seasonal factors, such as the use of the snow cover

400 product (MOD10_L2) to check the presence of occasional water, snow or ice in an area,

401 or the use of the vegetation index product (MOD13_VI) to determine the greenness of

402 senescent vegetation. Presently, three different versions of this product (V4, V41 and V5)

403 are available; for the comparison, the V41 was chosen because it addresses

404 underestimation problems in the V5 Climate Modeling Grid (CMG) products, and the

405 production date for this collection starts with MODIS/Terra data acquisition from January 4062007.

407 In order to do the comparison, equivalent MOD11_L2 composite maps over 408 Europe were produced monthly by averaging the data provided by the MOD11A2 409 product on an eight-day basis using a sinusoidal projection. After the MOD11_L2 410 monthly maps were generated, emissivity differences were calculated in a pixel-by-pixel 411 basis (MODIS LSE minus AATSR LSE) for the two split-window channels. Figure 6 412 shows the emissivity difference maps for January, April, July and October, Figure 7 413 presents the histograms of the difference data for the same months, and Table 4 gives the 414 summary statistics for the results.

415 Most of the observed differences are within \pm 0.01 in emissivity, with average 416 values for the whole scene around zero in all seasons, below the expected error of 417 estimate described in the sensitivity analysis subsection. The temporal comparison shows 418 that in January MODIS emissivities are +0.01 larger than AATSR emissivities in most 419 places and for the two channels (this bias is larger for channel at $12 \mu \mathrm{m}$ ), except in 420 northern Europe. For the other seasons this bias is significantly reduced. The spatial 421 patterns of the difference maps show that the larger disparity between both products is 
422 grouped geographically. The majority of the differences between +0.01 and +0.02 are

423 located in southern Europe (Portugal, Spain, and Italy). Oppositely, the differences lower

424 than -0.02 are located in Scandinavia, and other high-altitude places such as the Alps,

425 where the presence of water and snow is more common. Thus, the proposed method is

426 providing higher emissivity values for places where snow and water are present, and

427 lower emissivity values in arid and semi-arid areas. These differences can be due to

428 several reasons: (i) the different land cover classification used in each case, the yearly

429 MOD12Q1 product in MODIS that can be more dynamic, and GLOBCOVER in AATSR

430 that is a static classification; (ii) the different emissivity coefficients used for each surface

431 type, especially for bare soil and rocky areas (these are higher in the MODIS case, which

432 could explain higher emissivity values in arid areas); (iii) the calculation of the effective

433 emissivity in case of AATSR is dynamic for vegetated surfaces since it is based on the

434 calculation of fractional vegetation cover from NDVI, while it is semi-static in MODIS

435 since this product does not estimate fractional vegetation covers, only estimates the

436 phenological state from vegetation index data and time of the year. Despite these

437 differences, the two products seem to be quite consistent, at least in relation to the 438 expected error of estimate in emissivity.

\section{4. SUMMARY AND CONCLUSIONS}

440 In this work a methodology for automatic generation of LSE maps is proposed that 441 was developed taking as starting point the Vegetation Cover Method (Valor and Caselles 442 1996). The new algorithm is based on the combination of VCM with a classification of

443 the land surface (GLOBCOVER), which allows: (i) considering all surfaces, not only 444 natural land surfaces related to vegetation cover, but also urban, water or snow areas, for 
445 instance; and (ii) adjusting the emissivity coefficients of the algorithm depending on the

446 different surface components and geometries, instead of using general coefficients

447 globally, reducing thus the error of estimate in LSE. In addition, the algorithm uses a

448 dynamic estimation of the fractional vegetation cover through the year that allows

449 capturing LSE variations due to changes at surface level, including the occasional 450 presence of water or snow.

451 The sensitivity analysis of the methodology shows that in most cases LSE can be 452 achieved with errors of the order of $\pm 1 \%$ or lower, which implies errors in LST lower 453 than $\pm 1 \mathrm{~K}$, except for the case of bare areas for which additional efforts will be needed 454 (including geologic/rock maps if available, or using a complementary methodology). 455 These results have been confirmed by a validation exercise comparing the LSE produced 456 by the algorithm to ground reference emissivity measurements conducted in rice fields in 457 the Albufera of Valencia, Spain, in two times of the year. However, the validation has 458 indicated that the selected emissivity value for dry bare soil should be revised considering 459 additional published datasets, especially for channel AATSR-12 $\mu \mathrm{m}$.

460 The proposed LSE maps for AATSR have been also compared to the equivalent 461 MODIS product (MOD11_L2) in the year 2007. The comparison resulted in emissivity 462 differences mostly within \pm 0.01 with average values for the whole scene around zero in 463 all seasons, below the expected error of estimate given by the sensitivity analysis. The 464 highest differences between products were observed temporally in January, and spatially 465 in southern Europe and Scandinavia.

466 The proposed methodology can be adapted to different present and future TIR 467 remote sensors, but in this work it has been applied to AATSR data over Europe, since it 
468 has been recognized the need of improvement in the LST operational product, in

469 particular using classification schemes with better spatial resolution. In fact, the

470 methodology here presented is part of an effort to improve AATSR LST estimations

471 through the use of a split-window algorithm with explicit dependence on emissivity (Coll

472 et al. 2012b). Further developments will include the improvement of LSE estimation over

473 bare areas, the production of global LST maps based on AATSR data with the proposed

474 LSE methodology, and also the adaptation to present and new TIR sensors.

\section{ACKNOWLEDGMENTS}

476 This work was funded by the Generalitat Valenciana (project PROMETEO/2009/086, 477 and contract of Eduardo Caselles) and the Spanish Ministerio de Ciencia e Innovación 478 (projects CGL2007-64666/CLI, CGL2010-17577/CLI and CGL2007-29819-E, co479 financed with FEDER funds). AATSR data were provided by European Space Agency 480 (ESA) under Cat-1 project 3466. We also thank ESA and the ESA GLOBCOVER 481 Project, led by MEDIAS-France, for the GLOBCOVER classification data. The 482 comments and suggestions of three anonymous reviewers that improved the paper are 483 also acknowledged. 


\section{REFERENCES}

486 Anderson, M.C., Norman, J.M., Kustas, W.P., Houborg, R., Starks, P.J. and Agam,

487 N. (2008). A thermal-based remote sensing technique for routine mapping of land488 surface carbon, water and energy fluxes from field to regional scales. Remote Sensing of 489 Environment, 12: 4227-4241.

490 Arino, O., Bicheron, P., Achard, F., Latham, J., Witt, R. and Weber, J.L. (2008).

491 "GlobCover: the most detailed portrait of Earth", ESA Bulletin 136, European Space 492 Agency.

493 Baldridge, A. M., Hook, S. J., Grove, C. I. and Rivera, G. (2009). The ASTER 494 Spectral Library Version 2.0. Remote Sensing of Environment, 113: 711-715.

495 Bartholomé, E. and Belward, A.S. (2005). GLC2000: a new approach to global land 496 cover mapping from Earth observation data. International Journal of Remote Sensing, 497 26(9): 1959-1977.

498 Bicheron, P., Huc, M., Henry, C., Bontemps, S. and Lacaux, J.P. (2008). Globcover: 499 Products Description Manual. Issue 2, 500 http://ionial.esrin.esa.int/images/GLOBCOVER_Product_Specification_v2.pdf.

501 Buttner, G., Feranec, J., Jaffrain, G., Mari, L., Maucha, G. and Soukup, T. (2004).

502 The European Corine Land Cover 2000 Project. XX Congress of International Society for 503 Photogrammetry and Remote Sensing. Istanbul, Turkey.

504 Caselles, V., and Sobrino, J.A. (1989). Determination of frosts in orange groves 505 from NOAA-9 AVHRR data. Remote Sensing of Environment, 29: 135-146.

506 Coll, C., Caselles, V., Galve, J.M., Valor, E., Niclòs, R. and Sánchez, J.M. (2006). 507 Evaluation of split-window and dual-angle correction methods for land surface 
508 temperature retrieval from Envisat/Advanced Along Track Scanning Radiometer

509 (AATSR) data. Journal of Geophysical Research, 111, doi:10.1029/2005JD006830.

510 Coll, C., Caselles, V., Valor, E., Niclòs, R., Sánchez, J.M., Galve, J.M. and Mira, M.

511 (2007). Temperature and emissivity separation from ASTER data for low spectral 512 contrast surfaces. Remote Sensing of Environment, 110: 162-175.

513 Coll, C., Hook, S.J. and Galve, J.M. (2009). Land Surface Temperature from the

514 Advanced Along-Track Scanning Radiometer: Validation Over Inland Waters and

515 Vegetated Surfaces. IEEE Transactions on Geoscience and Remote Sensing, 47: 350-360.

516 Coll, C., Galve, J.M., Sánchez, J.M. and Caselles, V. (2010) . Validation of Landsat-

517 7/ETM+ thermal-band calibration and atmospheric correction with ground-based

518 measurements. IEEE transactions on Geoscience and Remote Sensing, 48 (1): 547-555.

519 Coll, C., Caselles, V., Valor, E. and Niclòs, R. (2012a). Comparison between

520 different sources of atmospheric profiles for land surface temperature retrieval from

521 single channel thermal infrared data. Remote Sensing of Environment 117: 199-210.

522 Coll, C., Valor, E., Galve, J.M., Mira, M., Bisquert, M., García-Santos, V., Caselles,

523 E. and Caselles, V. (2012b). Long-term accuracy assessment of land surface temperatures

524 derived from the Advanced Along-Track Scanning Radiometer. Remote Sensing of 525 Environment, 116: 211-225.

526 Cristóbal, J., Jiménez-Muñoz, J.C., Sobrino, J.A., Ninyerola, M. and Pons, X. 527 (2009). Improvements in land surface temperature retrieval from the Landsat series 528 thermal band using water vapor and air temperature. Journal of Geophysical Research 529 114, doi 10.1029/2008JD010616. 
Di Gregorio, A. and Jansen, L. (2000). Land Cover Classification System (LCCS):

531 Classification Concepts and User, FAO Corporate Document Repository.

532 Friedl, M.A., McIver, D.,K., Hodges, J.C.F., Zhang, X.Y., Muchoney, D., Strahler,

533 A.H., Woodcock, C.E., Gopal, S., Schneider, A., Cooper, A., Baccini, A., Gao, F. and

534 Schaaf, C. (2002). Global land cover mapping from MODIS: algorithms and early results.

535 Remote Sensing of Environment 83: 287-302.

536 Friedl, M.A., Sulla-Menashe, D., Tan, B., Schneider, A., Ramankutty, N., Sibley, A.

537 and Huang, X. (2010). MODIS Collection 5 global land cover: algorithm refinements and

538 characterization of new datasets. Remote Sensing of Environment, 114: 168-182.

539 Galve J.M., Coll, C., Caselles V. and Valor E. (2008). An atmospheric

540 radiosounding database for generating Land Surface Temperature algorithms. IEEE

541 Transactions on Geosciences and Remote Sensing, 46 (5): 1547-57.

542 Gillespie, A.R., Matsunaga, T., Rokugawa, S., and Hook, S. J. (1998). Temperature

543 and emissivity separation from Advanced Spaceborne Thermal Emission and Reflection

544 Radiometer (ASTER) images. IEEE Transactions on Geoscience and Remote Sensing,

545 36: 1113-1125.

546 Gutman, G. and Ignatov, A. (1998). The derivation of green vegetation fraction from

547 NOAA/AVHRR data for use in numerical weather prediction models. International 548 Journal of Remote Sensing, 19 (8): 1533-1543.

549 Hall, D. K., Riggs, G. A., Salomonson, V. V., DeGirolamo, N. E., Bayr, K. J., and

550 Jin, J. M. (2002). MODIS Snow-cover products. Remote Sensing of Environment, 83:

551 181- 194. 
Herold, M., Mayaux, P., Woodcock, C.E., Baccini, A., and Schmullius, C. (2008).

553 Some challenges in global land cover mapping: An assessment of agreement and 554 accuracy in existing $1 \mathrm{~km}$ datasets. Remote Sensing of Environment, 112: 2538-2556.

555 Heiskanen, J. (2008). Evaluation of global land cover data sets over the tundra-taiga 556 transition zone in northernmost Finland. International Journal of Remote Sensing, 557 29(13): 3727-3751.

558 Jiang, ZY, Huete, AR, Chen, J, Chen, YH, Li, J, Yan, GJ, Zhang, XY (2006).

559 Analysis of NDVI and scaled difference vegetation index retrievals of vegetation 560 fraction. Remote Sensing of Environment 101: 366-378.

561 Jin, M. and Liang, S. (2006). An Improved Land Surface Emissivity Parameter for

562 Land Surface Models Using Global Remote Sensing Observations. Journal of Climate, 563 19: 2867-2881.

564 Jung, M., Henkel, K., Herold, M. and Churkina, G. (2006). Exploiting synergies of 565 global land cover products for carbon cycle modelling. Remote Sensing of Environment, $566 \quad 101: 534-553$.

567 Lentile, L.B., Holden, Z.A., Smith, A.M.S., Falkowski, M.J., Hudak, A.T., Morgan, 568 P., Lewis, S.A., Gessler, P.E., and Benson, N.C. (2006). Remote sensing techniques to 569 assess active fire characteristics and post-fire effects._International Journal of Wildland 570 Fire 15: 319-345.

571 Li, Z.-L., and Becker, F. (1993). Feasibility of land surface temperature and 572 emissivity determination from AVHRR data. Remote Sensing of Environment, 43: 67-85. 
573 Liang, S., Kustas, W., Schaepman-Strub, G., and Li, X. (2010). Impacts of climate

574 change and land use change on land surface radiation and energy budgets. IEEE Journal

575 of Selected Topics in Earth Observations and Remote Sensing 3: 219-224.

576 Loveland, T.R., Reed, B.C., Brown, J.F., Ohlen, D.O., Zhu, Z., Yang, L. and

577 Merchant, J.W. (2000). Development of a global land cover characteristics database and

578 IGBP DISCover from $1 \mathrm{~km}$ AVHRR data. International Journal of Remote Sensing, 21:

$579 \quad 1303-1330$.

580 Mira, M., Valor, E., Boluda, R., Caselles, V., and Coll, C. (2007). Influence of soil

581 water content on the thermal infrared emissivity of bare soils: Implication for land 582 surface temperature determination. Journal of Geophysical Research 112, doi: $583 \quad 10.1029 / 2007 J F 000749$.

584 Neumann, K., Herold, M., Hartley, A. and Schmullius, C. (2007). Comparative 585 assessment of CORINE2000 and GLC2000: Spatial analysis of land cover data for 586 Europe. International Journal of Applied Earth Observation and Geoinformation, 9: $587 \quad 425-437$.

588 Noyes, E., G. Corlett, J. Remedios, X. Kong, and D. Llewellyn-Jones (2007). An 589 Accuracy Assessment of AATSR LST Data Using Empirical and Theoretical Methods. 590 Proceedings of the Envisat Symposium 2007, Montreux, Switzerland, ESA SP-636.

591 Peres, L.F., and DaCamara, C.C. (2005). Emissivity maps to retrieve land-surface 592 temperature from MSG/SEVIRI. IEEE Transactions on Geoscience and Remote Sensing, 593 43: 1834-1844. 
594 Purevdorj, Ts., Tateishi, R., Ishiyama, T. and Honda, Y. (1998). Relationships

595 between percent vegetation cover and vegetation indices. International Journal of 596 Remote Sensing 19 (18): 3519-3535.

597 Riggs, G. A., Barton, J. S., Casey, K. A., Hall, D. K., and Salomonson, V. V. 598 (2000). MODIS Snow Products Users’ Guide.

599 http://www.icess.ucsb.edu/modis/SnowUsrGuide/usrguide.html.

600 Rubio, E., Caselles, V., Coll, C., Valor, E., and Sospedra, F. (2003). Thermal601 infrared emissivities of natural surfaces: improvements on the experimental set-up and 602 new measurements. International Journal of Remote Sensing 24: 5379-5390.

603 See, L.M., and Fritz, S. (2006). A Method to Compare and Improve Land Cover 604 Datasets: Application to the GLC-2000 and MODIS Land Cover Products. IEEE 605 Transactions on Geoscience and Remote Sensing 44 (7): 1740-1746.

606 Snyder,W. C., and Wan Z. (1998). BRDF models to predict spectral reflectance and 607 emissivity in the thermal infrared. IEEE Transactions on Geoscience and Remote Sensing 608 36: 214- 225.

609 Snyder, W.C., Wan, Z., Zhang, Y., and Feng, Y.Z. (1998). Classification-based 610 emissivity for land surface temperature measurement from space. International Journal 611 of Remote Sensing 19: 2753-2774.

612 Sòria, G. and Sobrino, J.A. (2007). ENVISAT/AATSR derived land surface 613 temperature over a heterogeneous region. Remote Sensing of Environment 111: 409-422.

614 Tralli, D.M., Blom, R.G., Zlotnicki, V., Donnellan, A. and Evans, D.L. (2005).

615 Satellite remote sensing of earthquake, volcano, flood, landslide and coastal inundation 616 hazards. ISPRS Journal of Photogrammetry and Remote Sensing, 59: 185-198. 
617 Trigo, I.F., Peres, L.F., DaCamara, C.C. and Freitas, S.C. (2008). Thermal land 618 surface emissivity retrieved from SEVIRI/Meteosat. IEEE Transactions on Geoscience 619 and Remote Sensing 46: 307-315.

620 Valor, E. and Caselles, V. (1996). Mapping Land Surface Emissivity from NDVI: 621 application to European, African, and South American Areas. Remote Sensing of 622 Environment 57: 167-184.

623 Verger, A., Martínez, B., Camacho-de Coca, F. and García-Haro, F.J. (2009).

624 Accuracy assessment of fraction of vegetation cover and leaf area index estimates from 625 pragmatic methods in a cropland area. International Journal of Remote Sensing 30 (10): $6262685-2704$.

627 Wan, Z. and Dozier, J. (1996). A generalized split-window algorithm for retrieving 628 land-surface temperature from space. IEEE Transactions on Geoscience and Remote 629 Sensing 34: 892-905.

630 Wan, Z., and Li, Z.-L. (1997). A physics-based algorithm for land-surface 631 emissivity and temperature from EOS/MODIS data. IEEE Transactions on Geoscience 632 and Remote Sensing 35: 980-996.

633 Watson, K. (1992). Two-temperature method for measuring emissivity. Remote 634 Sensing of Environment 42: 117-121.

635 Wu, W., Shibasaki, R., Yang, P., Ongaro, L., Zhou, Q., and Tang, H. (2008). 636 Validation and comparison of $1 \mathrm{~km}$ global land cover products in China. International 637 Journal of Remote Sensing 29(13): 3769-3785. 
638 Xiao, J. and Moody, A. (2005). A comparison of methods for estimating fractional 639 green vegetation cover within a desert-to-upland transition zone in central New Mexico, 640 USA. Remote Sensing of Environment 98: 237-250.

641 Yu, Y., Privette, J.L. and Pinheiro, A.C. (2008). Evaluation of Split-Window Land 642 Surface Temperature Algorithms for Generating Climate Data Records. IEEE 643 Transactions on Geoscience and Remote Sensing 46: 179-192.

644 Zeng, X., Dickinson, R.E., Walker, A., Shaikh, M., DeFries, R.S. and Qi, J. (2000). 645 Derivation and evaluation of global 1-km fractional vegetation cover data for land 646 modeling. Journal of Applied Meteorology 39: 826-839.

647 Zhou, X., Guan, H., Xie, H. and Wilson, J.L. (2009). Analysis and optimization of 648 NDVI definitions and areal fraction models in remote sensing of vegetation. International 649 Journal of Remote Sensing 33 (3): 721-751.

650 Zhou, J., Li, J., Zhang, L., Hu, D. and Zhan, W. (2012). Intercomparison of methods 651 for estimating land surface temperature from a Landsat-5 TM image in an arid region 652 with low water vapour in the atmosphere. International Journal of Remote Sensing 33: $653 \quad 2582-2602$.

654 Zhukov, B., Lorenz, E., Oertel, D., Wooster, M.J., Roberts, G. (2006). Spaceborne 655 detection and characterization of fires during the bi-spectral infrared detection (BIRD) 656 experimental small satellite mission (2001-2004). Remote Sensing of Environment 100: $657 \quad 29-51$. 
659 Table 1. Emissivity classes by surface type, and their correspondence with the biomes defined by 660 the GLOBCOVER (GLC) dataset (after Coll et al. 2012b). The percentage occurrence over 661 Europe of each emissivity class is given in parentheses in the first column.

\begin{tabular}{|c|c|c|}
\hline Emissivity class & $\begin{array}{l}\text { GLC } \\
\text { Class }\end{array}$ & Description \\
\hline \multirow{4}{*}{$\begin{array}{l}\text { 1. Flooded } \\
\text { vegetation, crops and } \\
\text { grasslands }(\mathbf{0 . 7 5 \% )}\end{array}$} & 11 & Post-flooding or irrigated croplands (or aquatic) \\
\hline & 13 & Post-flooding or irrigated herbaceous crops \\
\hline & 180 & $\begin{array}{l}\text { Closed to open }(>15 \%) \text { grassland or woody vegetation on regularly flooded or } \\
\text { waterlogged soil - Fresh, brackish or saline water }\end{array}$ \\
\hline & 185 & $\begin{array}{l}\text { Closed to open }(>15 \%) \text { grassland on regularly flooded or waterlogged soil - Fresh } \\
\text { or brackish water }\end{array}$ \\
\hline $\begin{array}{l}\text { 2. Flooded forest and } \\
\text { shrublands }(<\mathbf{0 . 0 1 \% )}\end{array}$ & 170 & $\begin{array}{l}\text { Closed }(>40 \%) \text { broadleaved forest or shrubland permanently flooded - Saline or } \\
\text { brackish water }\end{array}$ \\
\hline \multirow{9}{*}{$\begin{array}{l}\text { 3. Croplands and } \\
\text { grasslands }(\mathbf{1 9 . 6 9 \% )}\end{array}$} & 14 & Rainfed croplands \\
\hline & 15 & Rainfed herbaceous crops \\
\hline & 20 & Mosaic cropland (50-70\%) / vegetation (grassland/shrubland/forest) (20-50\%) \\
\hline & 21 & Mosaic cropland (50-70\%) / grassland or shrubland $(20-50 \%)$ \\
\hline & 120 & Mosaic grassland (50-70\%) / forest or shrubland (20-50\%) \\
\hline & 140 & $\begin{array}{l}\text { Closed to open ( }>15 \%) \text { herbaceous vegetation (grassland, savannas or } \\
\text { lichens/mosses) }\end{array}$ \\
\hline & 141 & Closed $(>40 \%)$ grassland \\
\hline & 150 & Sparse $(<15 \%)$ vegetation \\
\hline & 151 & Sparse $(<15 \%)$ grassland \\
\hline \multirow{6}{*}{$\begin{array}{l}\text { 4. Shrublands } \\
(\mathbf{3 . 2 4 \% )}\end{array}$} & 16 & Rainfed shrub or tree crops (cash crops, vineyards, olive tree, orchards...) \\
\hline & 30 & Mosaic vegetation (grassland/shrubland/forest) (50-70\%) / cropland (20-50\%) \\
\hline & 130 & $\begin{array}{l}\text { Closed to open }(>15 \%) \text { (broadleaved or needleleaved, evergreen or deciduous) } \\
\text { shrubland }(<5 \mathrm{~m})\end{array}$ \\
\hline & 131 & Closed to open $(>15 \%)$ broadleaved or needleleaved evergreen shrubland $(<5 \mathrm{~m})$ \\
\hline & 134 & Closed to open $(>15 \%)$ broadleaved deciduous shrubland $(<5 \mathrm{~m})$ \\
\hline & 152 & Sparse $(<15 \%)$ shrubland \\
\hline \multirow{5}{*}{$\begin{array}{l}\text { 5. Broadleaved/ } \\
\text { needleleaved } \\
\text { deciduous forest } \\
\mathbf{( 1 0 . 3 7 \% )}\end{array}$} & 40 & Closed to open $(>15 \%)$ broadleaved evergreen or semi-deciduous forest $(>5 \mathrm{~m})$ \\
\hline & 50 & Closed $(>40 \%)$ broadleaved deciduous forest $(>5 \mathrm{~m})$ \\
\hline & 60 & Open $(15-40 \%)$ broadleaved deciduous forest/woodland $(>5 \mathrm{~m})$ \\
\hline & 90 & Open $(15-40 \%)$ needleleaved deciduous or evergreen forest $(>5 \mathrm{~m})$ \\
\hline & 91 & Open $(15-40 \%)$ needleleaved deciduous forest $(>5 \mathrm{~m})$ \\
\hline \multirow{6}{*}{$\begin{array}{l}\text { 6. Broadleaved/ } \\
\text { needleleaved } \\
\text { evergreen forest } \\
(\mathbf{6 . 4 6 \% )}\end{array}$} & 32 & Mosaic forest (50-70\%) / cropland (20-50\%) \\
\hline & 70 & Closed $(>40 \%)$ needleleaved evergreen forest $(>5 \mathrm{~m})$ \\
\hline & 92 & Open $(15-40 \%)$ needleleaved evergreen forest $(>5 \mathrm{~m})$ \\
\hline & 100 & Closed to open $(>15 \%)$ mixed broadleaved and needleleaved forest $(>5 \mathrm{~m})$ \\
\hline & 101 & Closed $(>40 \%)$ mixed broadleaved and needleleaved forest $(>5 \mathrm{~m})$ \\
\hline & 110 & Mosaic forest or shrubland (50-70\%) / grassland (20-50\%) \\
\hline $\begin{array}{l}\text { 7. Urban area } \\
(\mathbf{0 . 4 5 \% )}\end{array}$ & 190 & Artificial surfaces and associated areas (Urban areas $>50 \%$ ) \\
\hline \multirow{4}{*}{ 8. Bare rock $(\mathbf{0 . 8 5} \%)$} & 200 & Bare areas \\
\hline & 201 & Consolidated bare areas (hardpans, gravels, bare rock, stones, boulders) \\
\hline & 202 & Non-consolidated bare areas (sandy desert) \\
\hline & 203 & Salt hardpans \\
\hline 9. Water $(\mathbf{5 7 . 2 \%})$ & 210 & Water bodies \\
\hline $\begin{array}{l}\text { 10. Snow and ice } \\
(\mathbf{0 . 9 9 \% )}\end{array}$ & 220 & Permanent snow and ice \\
\hline
\end{tabular}


Table 2. Emissivity classes with the values for the parameters of equation (1) in the AATSR-11 and AATSR-12 $\mu$ m channels (after Coll et al. 2012b). In classes 1 and 2, (d) stands for a dry (non-flooded) surface with a soil as background, and (w) stands for a wet (flooded) surface.

\begin{tabular}{|c|c|c|c|c|c|c|}
\hline \multirow{2}{*}{ Emissivity Class } & \multicolumn{3}{|c|}{ AATSR-11 $\mu \mathrm{m}$} & \multicolumn{3}{|c|}{ AATSR-12 $\mu \mathrm{m}$} \\
\hline & $\varepsilon_{\mathrm{v}}$ & $\varepsilon_{\mathrm{g}}$ & $<\mathbf{d} \varepsilon>$ & $\varepsilon_{\mathrm{v}}$ & $\varepsilon_{\mathrm{g}}$ & $<\mathbf{d} \varepsilon>$ \\
\hline $\begin{array}{l}\text { 1. Flooded vegetation/ } \\
\text { crops/grasslands }\end{array}$ & $0.983 \pm 0.005$ & $\begin{array}{l}0.970 \pm 0.005(\mathrm{~d}) \\
0.991 \pm 0.001(\mathrm{w})\end{array}$ & 0 & $0.989 \pm 0.005$ & $\begin{array}{l}0.977 \pm 0.004(d) \\
0.985 \pm 0.001(w)\end{array}$ & 0 \\
\hline 2. Flooded forest/shrubland & $0.981 \pm 0.008$ & $\begin{array}{l}0.970 \pm 0.005(\mathrm{~d}) \\
0.991 \pm 0.001(\mathrm{w})\end{array}$ & $\begin{array}{l}0.014 \pm 0.004(\mathrm{~d}) \\
0.004 \pm 0.001(\mathrm{w})\end{array}$ & $0.982 \pm 0.009$ & $\begin{array}{l}0.977 \pm 0.004(\mathrm{~d}) \\
0.985 \pm 0.001(\mathrm{w})\end{array}$ & $\begin{array}{l}0.010 \pm 0.003(\mathrm{~d}) \\
0.007 \pm 0.002(\mathrm{w})\end{array}$ \\
\hline 3. Croplands/grasslands & $0.983 \pm 0.005$ & $0.970 \pm 0.005$ & 0 & $0.989 \pm 0.005$ & $0.977 \pm 0.004$ & 0 \\
\hline 4. Shrublands & $0.981 \pm 0.008$ & $0.970 \pm 0.005$ & $0.014 \pm 0.004$ & $0.982 \pm 0.009$ & $0.977 \pm 0.004$ & $0.010 \pm 0.003$ \\
\hline $\begin{array}{l}5 . \\
\text { Broadleaved/needleleaved } \\
\text { deciduous forest }\end{array}$ & $0.973 \pm 0.005$ & $0.970 \pm 0.005$ & $0.019 \pm 0.006$ & $0.973 \pm 0.005$ & $0.977 \pm 0.004$ & $0.015 \pm 0.004$ \\
\hline $\begin{array}{l}6 . \\
\text { Broadleaved/needleleaved } \\
\text { evergreen forest }\end{array}$ & $0.989 \pm 0.005$ & $0.970 \pm 0.005$ & $0.019 \pm 0.005$ & $0.991 \pm 0.005$ & $0.977 \pm 0.004$ & $0.015 \pm 0.004$ \\
\hline 7. Urban area & $0.980 \pm 0.005$ & & & $0.986 \pm 0.005$ & & \\
\hline 8. Bare rock & $0.93 \pm 0.05$ & & & $0.95 \pm 0.05$ & & \\
\hline 9. Water & $0.991 \pm 0.001$ & & & $0.985 \pm 0.001$ & & \\
\hline 10. Snow and ice & $0.990 \pm 0.004$ & & & $0.971 \pm 0.014$ & & \\
\hline
\end{tabular}


Table 3. Errors in emissivity in the AATSR-11 and AATSR-12 $\mu \mathrm{m}$ channels for the different vegetated and non-vegetated classes. The average,

668 standard deviation, maximum and minimum values of the errors when vegetation fraction ranges from 0 to 1, are presented. In classes 1 and 2, (d) stands for a dry (non-flooded) surface with a soil as background, and (w) stands for a wet (flooded) surface.

\begin{tabular}{|c|c|c|c|c|c|c|c|c|}
\hline \multirow[b]{2}{*}{ Emissivity Class } & \multicolumn{4}{|c|}{ AATSR-11 $\mu \mathrm{m}$} & \multicolumn{4}{|c|}{ AATSR-12 $\mu \mathrm{m}$} \\
\hline & avg & std dev & $\max$ & $\min$ & avg & std dev & $\max$ & $\min$ \\
\hline \multirow{2}{*}{$\begin{array}{l}\text { 1. Flooded vegetation/ } \\
\text { crops/grasslands }\end{array}$} & $0.007(d)$ & $0.000(\mathrm{~d})$ & $0.007(\mathrm{~d})$ & $0.007(\mathrm{~d})$ & $0.006(\mathrm{~d})$ & $0.000(d)$ & $0.007(d)$ & $0.007(d)$ \\
\hline & $0.004(w)$ & $0.001(\mathrm{w})$ & $0.006(\mathrm{w})$ & $0.002(\mathrm{w})$ & $0.004(w)$ & $0.001(\mathrm{w})$ & $0.006(\mathrm{w})$ & $0.002(\mathrm{w})$ \\
\hline \multirow{2}{*}{ 2. Flooded forest/shrubland } & $0.014(\mathrm{~d})$ & $0.001(\mathrm{~d})$ & $0.015(\mathrm{~d})$ & $0.011(\mathrm{~d})$ & $0.012(\mathrm{~d})$ & $0.001(d)$ & $0.014(\mathrm{~d})$ & $0.010(\mathrm{~d})$ \\
\hline & $0.007(\mathrm{w})$ & $0.003(\mathrm{w})$ & $0.012(\mathrm{w})$ & $0.002(\mathrm{w})$ & $0.008(w)$ & $0.003(\mathrm{w})$ & $0.014(\mathrm{w})$ & $0.005(\mathrm{w})$ \\
\hline 3. Croplands/grasslands & 0.007 & 0.000 & 0.007 & 0.007 & 0.006 & 0.000 & 0.007 & 0.006 \\
\hline 4. Shrublands & 0.014 & 0.001 & 0.015 & 0.011 & 0.012 & 0.001 & 0.014 & 0.010 \\
\hline $\begin{array}{l}\text { 5. Broadleaved/needleleaved } \\
\text { deciduous forest }\end{array}$ & 0.015 & 0.002 & 0.017 & 0.011 & 0.012 & 0.002 & 0.015 & 0.009 \\
\hline $\begin{array}{l}\text { 6. Broadleaved/needleleaved } \\
\text { evergreen forest }\end{array}$ & 0.014 & 0.003 & 0.019 & 0.010 & 0.012 & 0.002 & 0.015 & 0.008 \\
\hline 7. Urban area & \multicolumn{4}{|l|}{0.005} & \multicolumn{4}{|l|}{0.005} \\
\hline 8. Bare rock & \multicolumn{4}{|l|}{0.05} & \multicolumn{4}{|l|}{0.05} \\
\hline 9. Water & \multicolumn{4}{|l|}{0.001} & \multicolumn{4}{|l|}{0.001} \\
\hline 10. Snow and ice & \multicolumn{4}{|l|}{0.004} & \multicolumn{4}{|l|}{0.014} \\
\hline
\end{tabular}


673 Table 4.- Summary statistics of the emissivity difference images for the different seasons of the year 2007 in each channel (11 and $12 \mu \mathrm{m})$.

\begin{tabular}{|c|c|c|c|c|c|c|c|c|}
\hline & \multicolumn{4}{|c|}{ Channel $11 \mu \mathrm{m}$} & \multicolumn{4}{|c|}{ Channel $12 \mu \mathrm{m}$} \\
\hline & January & April & July & October & \begin{tabular}{|l} 
January \\
\end{tabular} & April & July & October \\
\hline Minimum & -0.03 & -0.03 & -0.03 & -0.03 & -0.02 & -0.02 & -0.03 & -0.02 \\
\hline Maximum & 0.02 & 0.02 & 0.02 & 0.02 & 0.02 & 0.02 & 0.02 & 0.02 \\
\hline Mean & 0 & 0 & 0 & 0 & 0 & 0 & 0 & 0 \\
\hline Standard deviation & 0.01 & 0.01 & 0.01 & 0.01 & 0.01 & 0 & 0.01 & 0.01 \\
\hline
\end{tabular}

679

680

681 


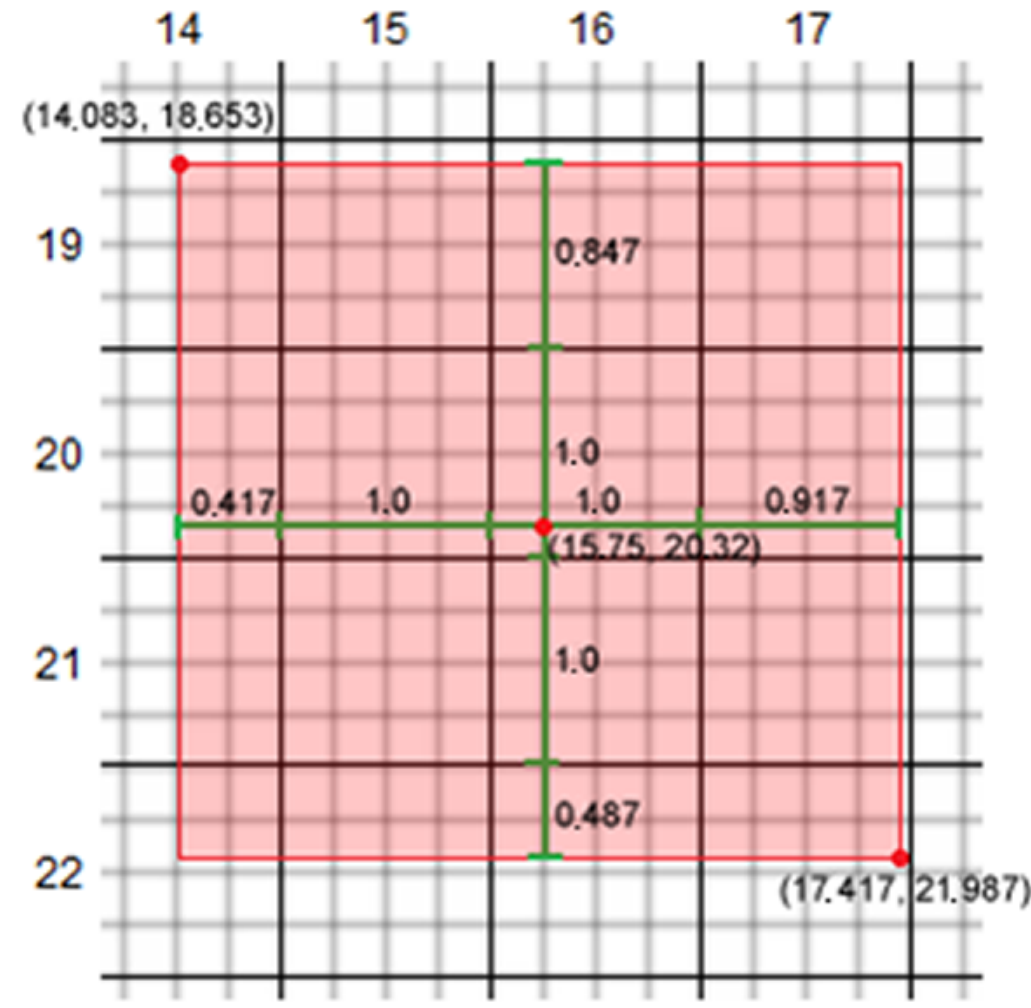

683 Figure 1.- Example of an AATSR pixel (1 km, shown in red), interpolated with GLC pixels (300 m, shown 684 in black), according to the interpolation by proportion of occupied areas algorithm. 


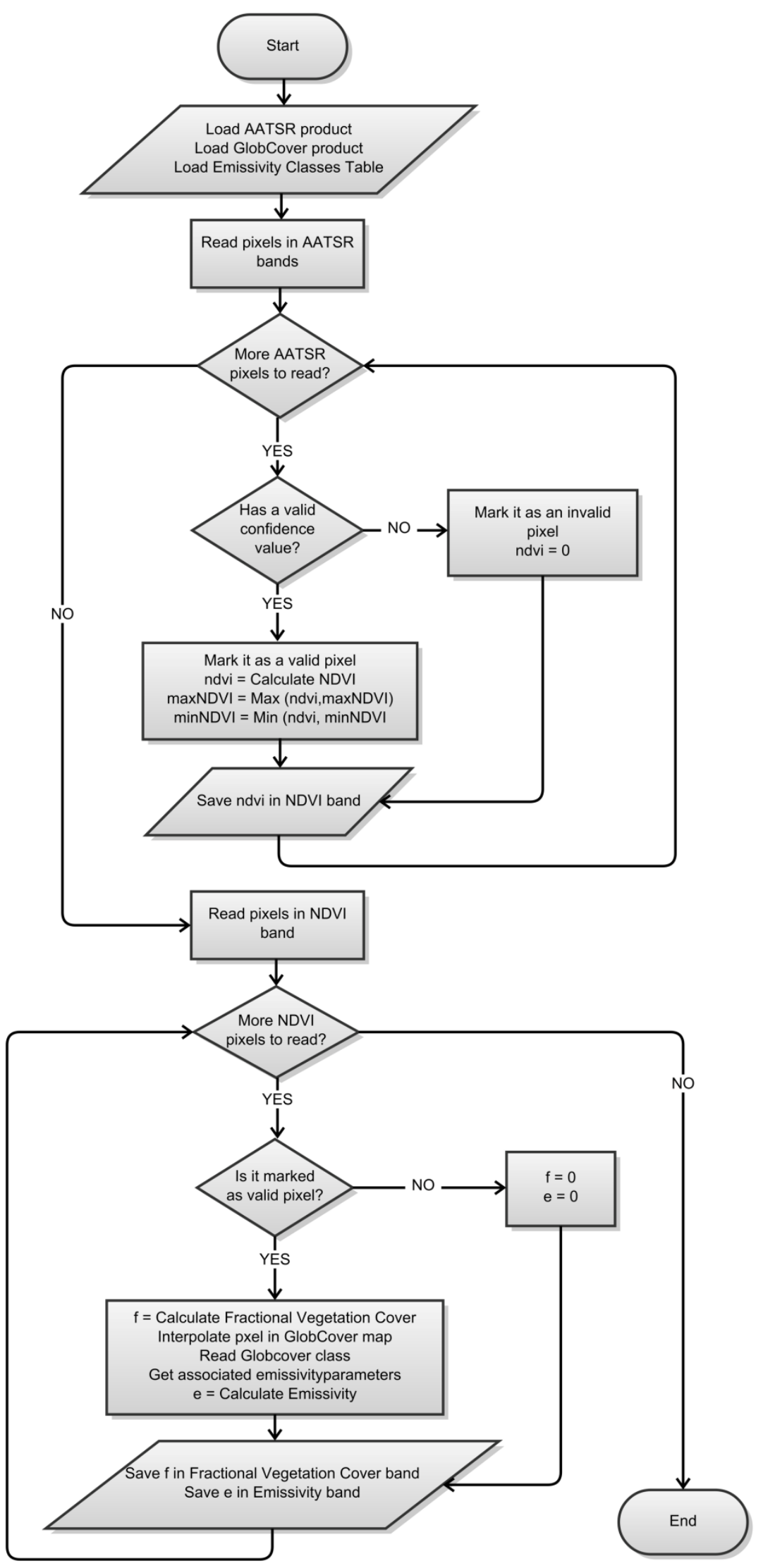

687 Figure 2.- Main flowchart of the system designed to produce emissivity maps for AATSR TIR channels. 

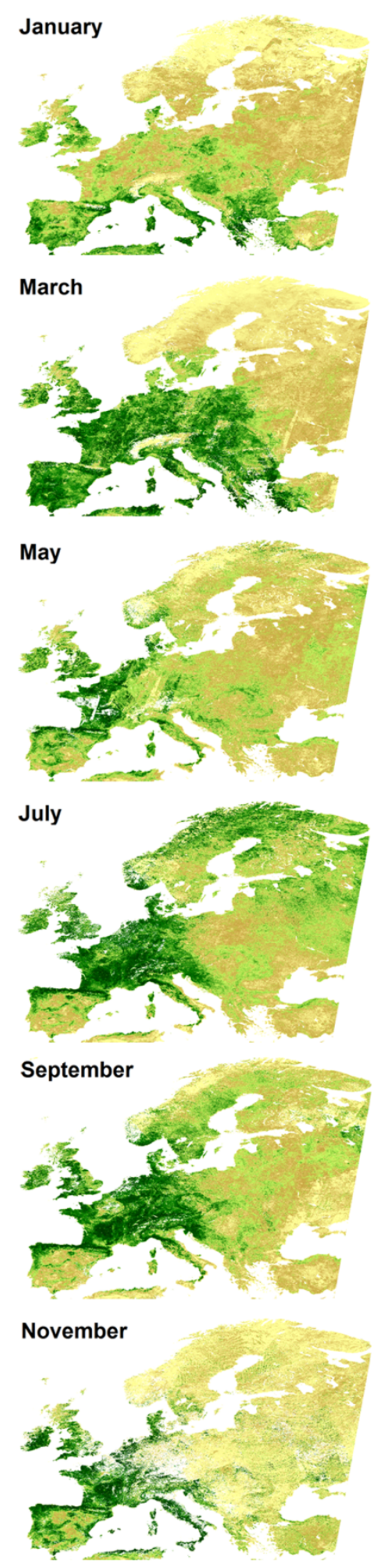
pixels correspond to water or cloudy areas.
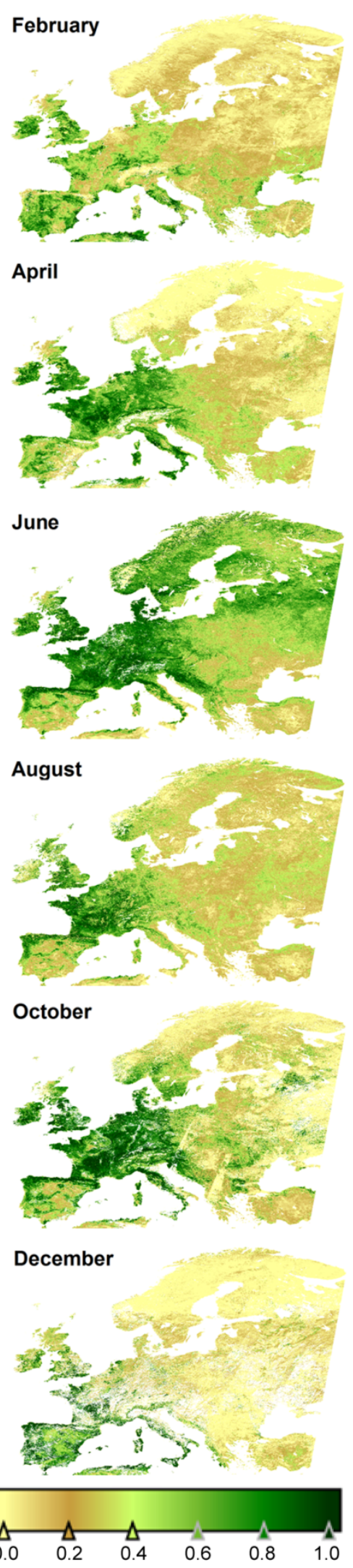

Figure 3.- Monthly fractional vegetation cover of Europe for year 2007. The monthly values have been calculated as the average of fractional vegetation covers over valid pixels in the considered month. White 

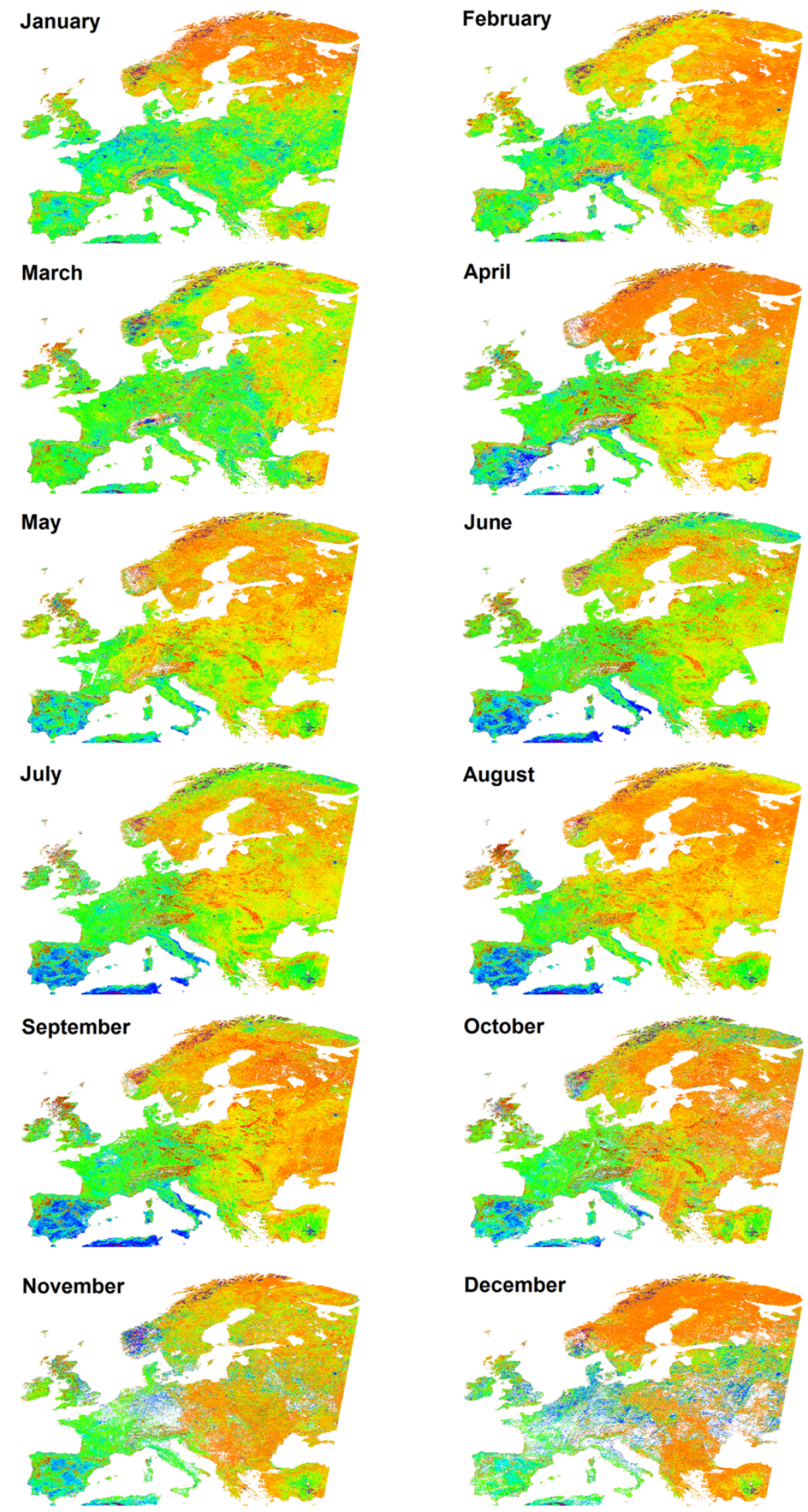

Figure 4.- Monthly emissivity in AATSR channel at $11 \mu \mathrm{m}$ over Europe for year 2007. The monthly values have been calculated as the average of emissivities over valid pixels in the considered month. 

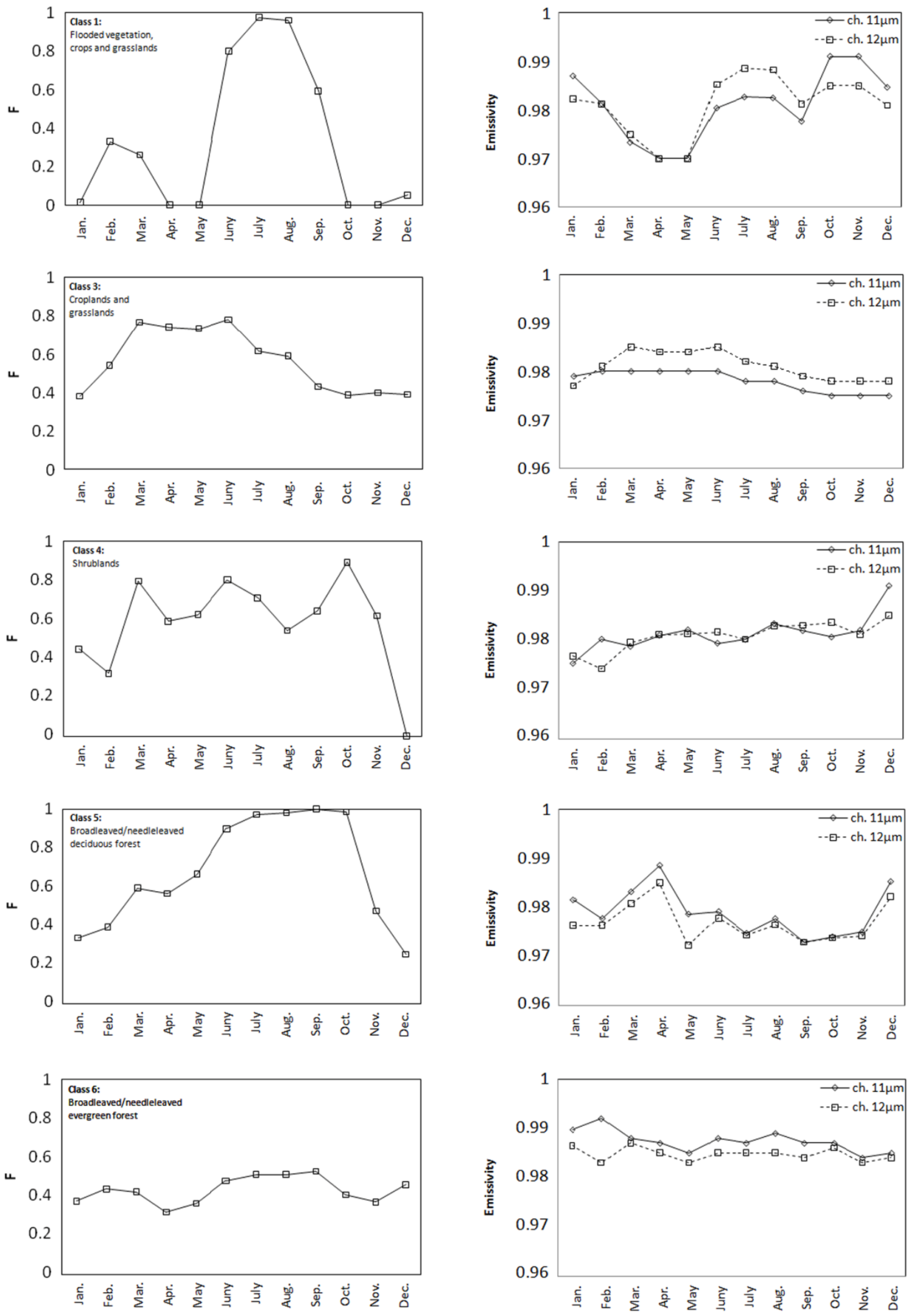

Figure 5.- Monthly evolution of fractional vegetation cover (graphs on the left) and emissivity (graphs on the right) for selected places corresponding to the different emissivity classes defined in Table 1 that are dependent on vegetation cover. 

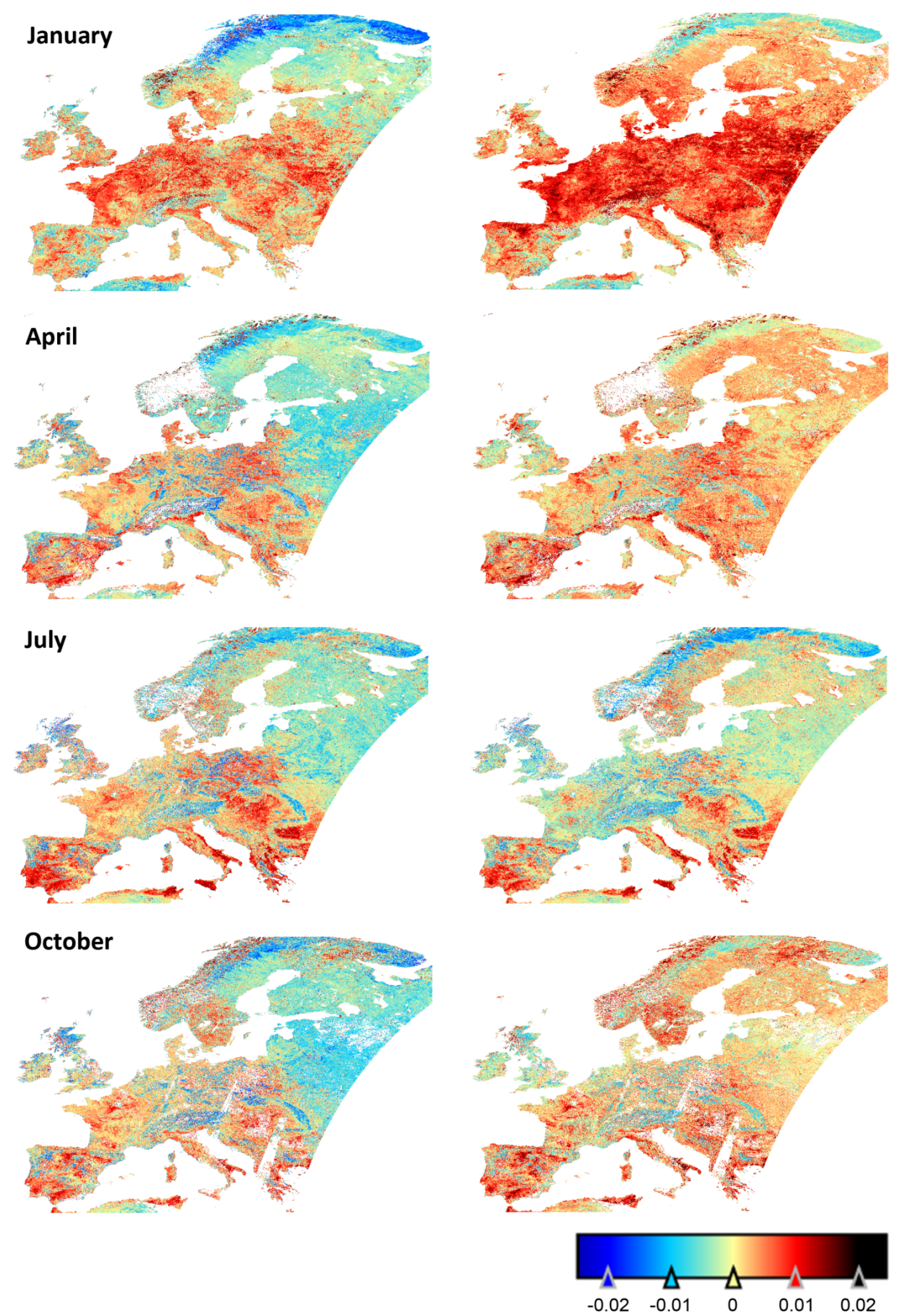

Figure 6.- Emissivity difference between the monthly emissivity estimates provided by the MODIS product 703 MOD11-L2 and the AATSR product proposed in this paper (MODIS LSE - AATSR LSE) for the two splitwindow channels, corresponding to the months of January, April, July and October. 

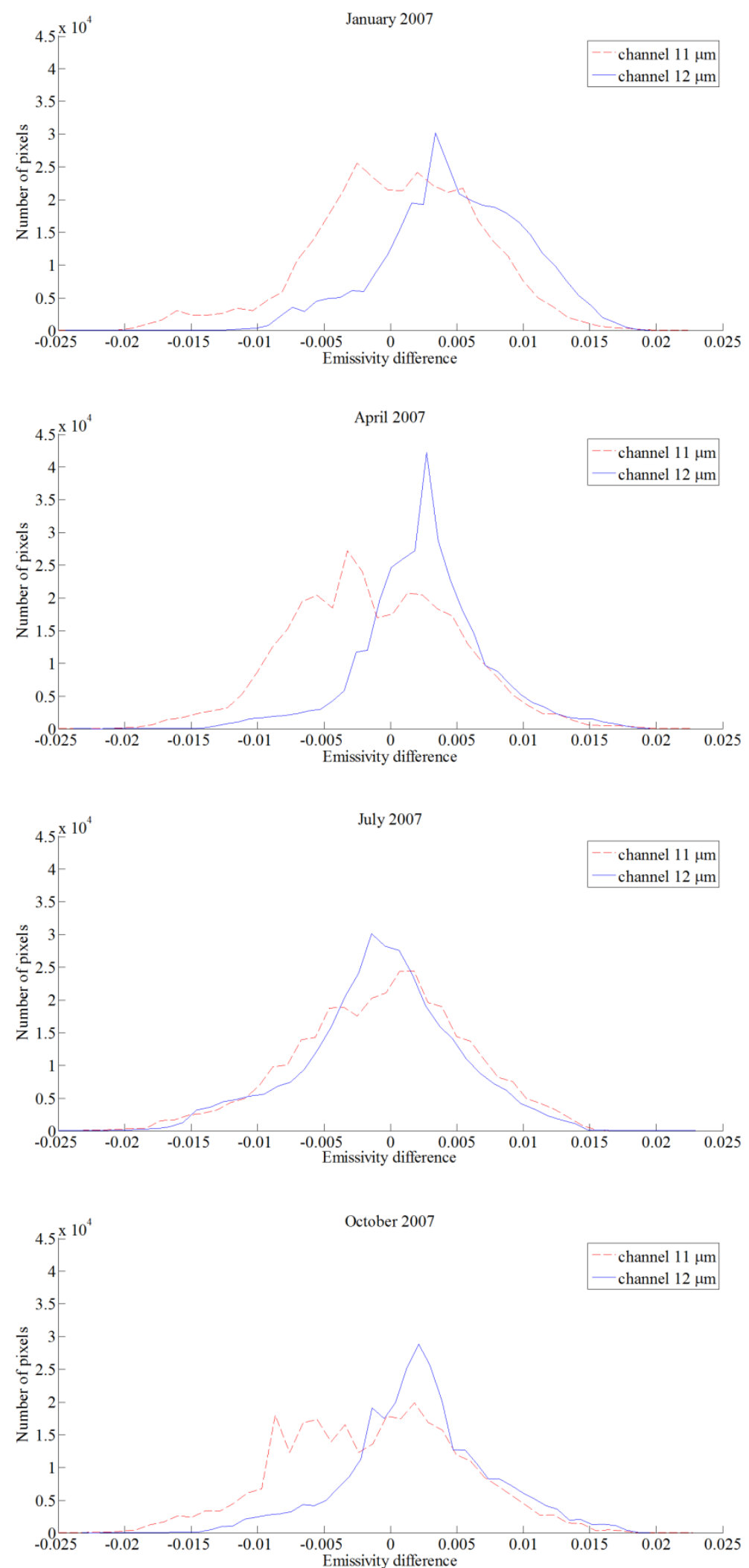

Figure 7.- Histograms of the emissivity differences between the monthly emissivity estimates provided by the MODIS product MOD11-L2 and the AATSR product proposed in this paper (MODIS LSE - AATSR LSE) for the two split-window channels, corresponding to the months of January, April, July and October. 